\title{
Microbiological Assessment of Raw Meat Used in Fast-Food Products Sold for Public Consumption
}

\author{
Gheorghe ILE, Alexandra TABARAN*, Sorin Daniel DAN, Romolica MIHAIU, Oana REGET \\ and Marian MIHAIU \\ ${ }^{1}$ Department of Animal Breeding and Food Safety, University of Agricultural Sciences and Veterinary \\ Medicine, Cluj-Napoca, Romania \\ *corresponding author: lapusan_alexandra@yahoo.com
}

Bulletin UASVM Veterinary Medicine 75(1)/2018

Print ISSN 1843-5270; Electronic ISSN 1843-5378

doi:10.15835/buasvmcn-vm:005017

\begin{abstract}
Raw meat contains sufficient nutrients to support microbial growth and because of that the proper surveillance of the meat products destined for public consumption is mandatory. The purpose of this study was to conduct a microbiological risk assessment regarding the safety of pork, chicken and beef meat products found in fast -food units from Transylvania area. One hundred and seventy samples of raw meat(n=35) and fried foods made of pork $(n=39)$, chicken( $n=45)$ and beef products $(n=51)$ were purchased randomly from 5 different fast-food units located in the study area.The determination performed in order to assess the safety was the total number of Enterobacteriaceae, evaluation of toxigenic E. coli and Salmonella spp. presence, which is also the parameter requested by the current regulation. The levels of contamination with Enterobacteriaceae that exceeded the current legislation limit were 6/39 (15\%), 6/45 (13\%) and 5/51 (9\%) in cooked pork, chicken and respectively beef meat. Given the similar rate of contaminations among these three categories of food there were no statistical differences noticed ( $p>0.05)$. Results showed that in 35 of 170 (20\%) collected food samples were found total Enterobacteriaceae count over $3 \mathrm{log} \mathrm{CFU} / \mathrm{g}$ and 12 of 170 (7\%) were found with coliform bacteria. Raw meat destined for fast-food industry can represent a risk for public health if hygiene and refrigerating conditions are not properly monitored.
\end{abstract}

Keywords: meat, risk, public, safety

\section{Introduction}

The family Enterobacteriaceae comprises a large group of Gram-negative non-spore-forming bacteria, some of which are important human and animal pathogens (Abdallah et al., 2015). Their presence in the environment makes it inevitable for some members to enter within particular food chains, such as the meat production chain. Their initial load in raw materials is predominantly kept under control by the correct application of Good Agricultural Practices (GAP) during primary production and subsequently during slaughter of livestock at the abattoir. During the processing stages, the contamination with possible Enterobacteriaceae pathogens must be prevented or controlled by the application of the quality assurance systems including Hazard Analysis and Critical Control Point (HACCP) systems and Good Manufacturing Practices (GMP) (Wheatley et al., 2014).

The busy and hectic life schedule has forced most of the consumers to choose the fast food products even though the methods of cooking or the raw materials used entirely healthy. In Romania, the most frequently consumed fast food meals are similar to those eaten in America namely burger, Pizza and fries and Kebab (Saadia, 2010). These meals normally are prepared after a common recipe, but there are situations when the consumer prefers the meat slightly cooked and 
therefore the hazard of food illnesses increases if contamination occurred in the raw material. Pathogens in fast and traditional foods are responsible for a high number of food poisonings. Salmonella is one of the most common causes of these episodes in humans, particularly in chicken burgers or chicken kebab (Woodward, 1996; Kaneko et al., 1999; Uyttendaele et al., 1999 and Angelillo et al., 2000).

Listeria spp. was reported also in retail foods, fast food environments and human sources (Kerr, 1993; MacGowan et al., 1994). Furthermore, it was reported the prevalence of Campylobacter spp., Staphylococcus spp., Escherichia coli, Salmonella spp., Yersinia spp. and Listeria on meat, sea foods, vegetable ingredients, chicken shaormas, raw and cooked foods, raw chicken, beef burger sandwiches, ready-to eat salad vegetables, commercial mayonnaise, frozen chicken, poultry products and on the hands of food workers (Kaneko et al., 1999; Pelczar et al., 2006). Because some meat products such as beef hamburgers and fried beef are processed at lower temperatures, their final bacterial counts include some of the more heat resistant vegetative bacteria such as the enterococci. Unless the technology ensures the prevention of development, such as hot packaging and rapid freezing, recontamination invariably occurs from equipment, food handlers, raw products or dust (Angelillo et al., 2000).

Foodborne disease or microbiological spoilage of food can result from the failure or inability to control microorganisms at one or more stages of food production (Melngaile, 2004). Therefore, the microbiological testing at various stages of this fast- food production is relevant to know and understand the characteristic trends in distribution of microbiological contamination (ICMSF, 2011; Schaffner, 2007; Burlingame and Pineiro, 2007; IFST, 1997). In Romania, testing is made in order to ensure that a proper quality of fast-product is maintained but unfortunately the surveillance procedure is not all the time adapted properly. Researches concerning a possible contamination during processing stages and also a possible improper way of storage have not yet been described in the current field literature. Therefore, the objective of this study was to evaluate the contamination rate of foodborne bacteria such as Eneterobacteriaceae level, Escherichia coli and Salmonella spp. presence in raw meat and fast- food products (fried, boiled, grilled, roasted or steamed chicken/pork/beef food) sold in various fast-food units in Romania.

\section{Materials and methods Collection of samples}

Raw meat and heat cooked fast-foods such as grilled and kebab chicken, fried pork and beef were chosen as the target of this study. One hundred and seventy samples of raw meat $(\mathrm{n}=35)$ and fried foods made of pork( $n=39)$, chicken( $n=45)$ and beef products $(n=51)$ were purchased randomly from 5 different fast-food units in Romania, found in Transylvania area (north-west area). Sample gathering was made during one year (April 2016 - April 2017), in this way having the possibility to examine samples obtained in each season. We have chosen this area of study giving the high number of fast-food units and the lack of data regarding the possible biological hazards. The collected samples were put in sterile plastic bags and were kept in $4-6^{\circ} \mathrm{C}$ during transport.

\section{Enterobacteriaceae plate count}

The determination of Enterobacteriaceae level in the samples investigated was made following the steps described in the international standard (ISO 4832, 2006). Briefly, $25 \mathrm{~g}$ of meat sample was homogenized with $225 \mathrm{~mL}$ of sterile $0.85 \%$ sodium chloride solution. Each $0.1 \mathrm{~mL}$ of $10^{2}$, $10^{3}$ and $10^{4}$ times diluted homogenized sample were spread on Enterobacteriaceae agar(VRBA) (Oxoid, UK) and incubated at $35^{\circ} \mathrm{C}$ for $24 \mathrm{~h}$. Viable cell counts were calculated from the number of developed colonies.

\section{Isolation and identification of Salmonella spp.}

The protocol for Salmonella spp. identification was applied in conformity with the standard horizontal method for detection, ISO 6579:2002. Briefly, $25 \mathrm{~g}$ of meat from each sample was homogenized initially with $225 \mathrm{~mL}$ of sterile buffered peptone water BPW(Lab M. Ltd. Toplay House UK)and incubated at $37^{\circ} \mathrm{C}$ for $24 \mathrm{~h}$. Each of 0.5 or $1.0 \mathrm{~mL}$ portions of pre-enriched BPW samples were transferred into $10 \mathrm{~mL}$ of Rappaport Vassiliadis (RV) broth (Lab M. Ltd. Toplay House, UK). The RV broth was incubated at $37^{\circ} \mathrm{Cfor} 24 \mathrm{~h}$. Following incubation, the cultures were streaked on Xylose Lysine Deoxycholate agar (XLD) (Oxoid, UK), and Rambach confirmation agar (Oxoid, UK), and incubated at $37^{\circ} \mathrm{C}$ for $24 \mathrm{~h}$. The specific 


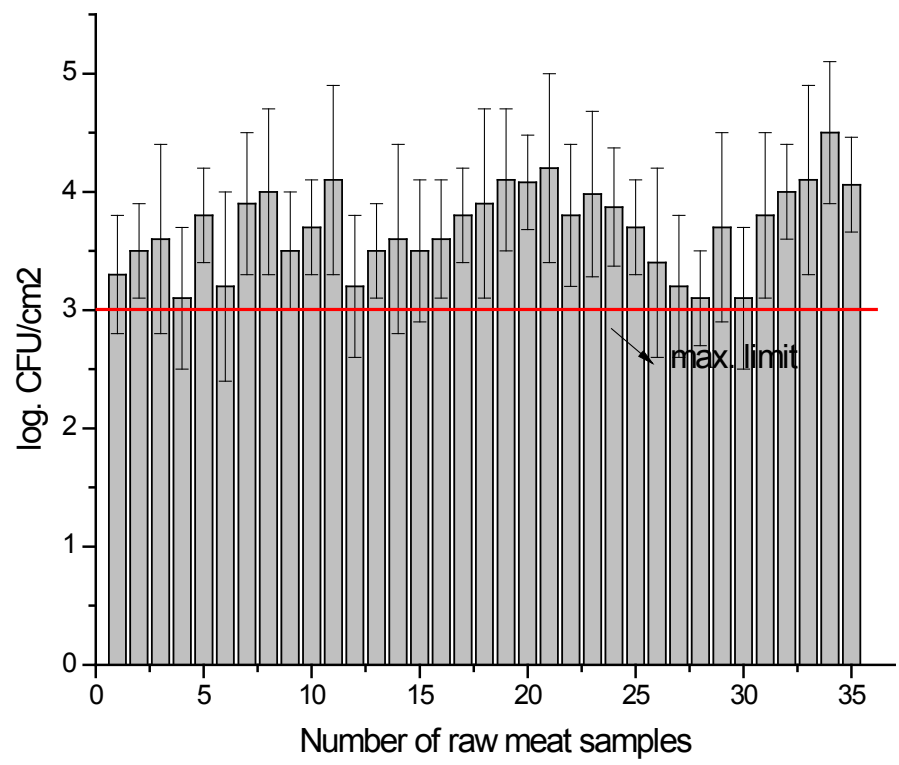

Figure 1. Enterobacteriaceae level in the raw meat destined for fast foods processing

Salmonella colonies were subjected to biochemical confirmation tests by using triple sugar iron agar, L Lysine decarboxytate agar and Simmon's citrate agar (Oxoid, UK) after purification on the same agar plates. API 20E (BioMérieux, France) diagnostic kits was also used to confirm these isolates.

Isolation and identification of Escherichia coli

For the isolation of $\beta$-glucuronidasepositive $E$. coli we followed the steps described in the standard protocol (ISO Standard 16649, 2001). Briefly, 25 $\mathrm{g}$ of meat from each sample was homogenized initially with $225 \mathrm{~mL}$ of sterile buffered peptone water BPW(Lab M. Ltd. Toplay House UK.1 mL was used to inculate plates that were already prepare with TBX (Tryptone, Bile salts and X- $\beta$-Dglucuronide) agar (Oxoid, UK).

\section{Statistical analysis}

Statistical analysis was performed using excel and Origin program version 8.5. The bacterial counts were expressed as mean \pm Standard deviation using excel. One way ANOVA followed by Turkey's post hoc test was used to compare the bacterial counts in various food samples. The mean difference was considered significant at $\mathrm{p}<$ 0.05 .

\section{Results and discussions}

The results of our study showed that in 35 of $170(20 \%)$ collected food samples were found total Enterobacteriaceae count over $3 \log \mathrm{CFU} / \mathrm{g}$ and 12 of $170(7 \%)$ were found with coliform bacteria.
We indicated that the rate of contamination in raw meat is high, as all the samples gathered had a higher level of Eneterobacteriaceae than the one stipulated by the current legislation (Reg. EC No. 2073/2005). The Enterobacteriaceae load levels are shown in figure 1.

The levels of contamination that exceeded the current legislation limit (NFSA Order 27/2011) were 6/39 (15\%), 6/45 (13\%) and 5/51 (9\%) in cooked pork, chicken and respectively beef meat (Fig. 2). Given the similar rate of contaminations among these three categories of food there were no statistical differences noticed.

Regarding the Salmonella spp. presence in the raw meat and cooked products studied, we did not find any positive samples. The contamination rate of $E$. coli in the raw meat samples was rather high as 28 out of 35 samples investigated (80\%) were positive. None of the E. coli strains isolated from the meat samples investigated were pathogenic. In the case of end-products, $14 / 39$ (36\%), 12/45 $(27 \%)$ and $16 / 51(31 \%)$ were found positive to E. coli presence in cooked pork, chicken meat and respectively beef meat.

There were no statistical differences noticed ( $>0.05$ ) among these categories of end-products studied regarding the presence of $E$. coli. However, pathogenic $E$. coli were not identified in any of the end-products samples investigated. Our study showed lower levels of contamination compared to similar researches performed previously in Thailand (Ananchaipattana et al., 2012). The 


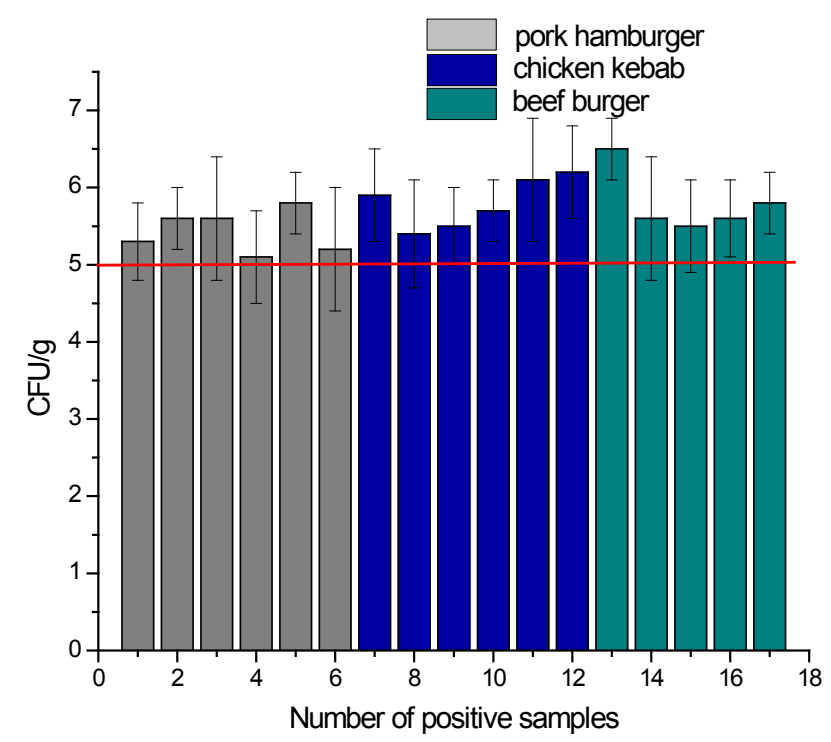

Figure 2. Enterobacteriaceae level in the positive samples of fast food products

Table 1. Contamination level in the samples examined

\begin{tabular}{|c|c|c|c|c|c|c|c|}
\hline \multirow[b]{2}{*}{ Specie } & \multirow[b]{2}{*}{ Bacteria } & \multicolumn{2}{|c|}{ Raw } & \multicolumn{2}{|c|}{ Cooked } & \multicolumn{2}{|c|}{ Total } \\
\hline & & $\begin{array}{c}\text { Positive } \\
\text { samples/ } \\
\text { total no. }\end{array}$ & Ratio (\%) & $\begin{array}{c}\text { Positive } \\
\text { samples/ } \\
\text { total no }\end{array}$ & Ratio (\%) & $\begin{array}{c}\text { Positive } \\
\text { samples/ } \\
\text { total no }\end{array}$ & Ratio (\%) \\
\hline \multirow{3}{*}{ Pork } & Enterobacteriaceae & $15 / 15$ & 100 & $6 / 39$ & 15 & $21 / 54$ & 38 \\
\hline & Salmonella spp. & $0 / 15$ & 0 & $0 / 39$ & 0 & $0 / 54$ & 0 \\
\hline & E. coli & $11 / 15$ & 73 & $14 / 39$ & 35 & $25 / 54$ & 46 \\
\hline \multirow{3}{*}{ Chicken } & Enterobacteriaceae & $10 / 10$ & 100 & $6 / 45$ & 13 & $16 / 55$ & 29 \\
\hline & Salmonella spp. & $0 / 10$ & 0 & $0 / 45$ & 0 & $0 / 55$ & 0 \\
\hline & E. coli & $8 / 10$ & 80 & $12 / 45$ & 26 & $20 / 45$ & 44 \\
\hline \multirow{3}{*}{ Beef } & Enterobacteriaceae & $10 / 10$ & 100 & $5 / 51$ & 9 & $15 / 61$ & 24 \\
\hline & Salmonella spp. & $0 / 10$ & 0 & $0 / 51$ & 0 & $0 / 61$ & 0 \\
\hline & E. coli & $9 / 10$ & 90 & $16 / 51$ & 31 & $25 / 61$ & 41 \\
\hline
\end{tabular}

distribution of Enterobacteriaceae in the meat processing units is primarily due to direct contact with the meat-handling surfaces. It was already proved by a previous study conducted by Stiles (1981) that the surfaces that do not come normally in contact with meats are not implicated as reservoirs of Enterobacteriaceae.

This particular study concluded that the Enterobacteriaceae on the meat contact surfaces are a buildup from meats and their ongoing handling. Therefore, in the units studied it is a problem given that all the samples of raw meat investigated exceeded the limit imposed by the current legislation.

Considering the high importance of $E$. coli and Salmonella infection organisms as food-borne pathogens, we aimed in this study to evaluate the possible presence of pathogenic strains and levels of contamination in meat-based fast food in Romania. Bacteriological analysis performed showed a differential distribution of these bacteria between different types of meats, even though none of the samples revealed a pathogenic strain. Normally the most frequent Enterobacteriaceae species isolated from contaminated meat are $E$. coli , K. pneumoniae, and S. liquefaciens. In the present study only E. coli was taken under surveillance but still we could state that the incidence of Enterobacteriaceae on cooked (processed)-meat products was dramatically reduced, as would be expected with the heat treatment. 


\section{Conclusions}

Our study revealed that the total number of Eneterobacteriaceae found in raw meat destined for fast food processing exceeds the limit imposed by the current legislation. The products processed afterwards by high temperatures are in a high percent in conformity with the legislation imposed. The microbial contamination may also come from other ingredients, that is why it is important to maintain the quality assurance systems. From the obtained results, we can conclude that contamination by pathogenic Escherichia coli and Salmonella is not a risk, none of the samples being positive. However, there are some recommendations that should be applied in the units studied. Routine microbiological examination should be performed to maintain the level of security given the exceeded level of Enterobacteriaceae and hygienic awareness should be applied for personnel that are involved in handling and preparing the meat.

Acknowledgments. This research did not receive any specific grant from funding agencies in the public, commercial, or not-for-profit sectors.

\section{References}

1. Abdallah HM, Reuland EA, Wintermans BB, al Naiemi N, Koek A, Abdelwahab AM, Vandenbroucke-Grauls CMJE (2015). Extended-Spectrum $\beta$-Lactamases and/or Carbapenemases-Producing Enterobacteriaceae Isolated from Retail Chicken Meat in Zagazig, Egypt. PLoS ONE, 10: e0136052.

2. Ananchaipattana C, Hosotani Y, Kawasaki S, Pongswat S, Latiful BM, Isobe S, Inatsu Y (2012). Bacterial contamination of soybean curd (Tofu) sold in Thailand. Food Science and Technology Research, 18: 843-848.

3. Angelillo IF, Viggiani NM, Rizzo L, Bianco A (2000). Food handlers and food borne disease: knowledge, attitude sand reported behavior in Italy. Journal of Food Protection, 63: 381-385.

4. Burlingame B, Pineiro M (2007). The essential balance: risks and benefits in food safety and quality. Journal of Food Composition and Analysis, 20: 139-146.
5. ICMSF (2011). Microorganisms in foods 8. Use of data for Assessing Process Control and Product Acceptance. New York: Springer. $400 \mathrm{~S}$.

6. IFST (1997). Development and use of microbiological criteria for foods. Food Science and Technology Today, 11: 137-176.

7. Kaneko K, Hayashidani H, Ohtomo Y, Kosuge J, Kato M, Takahashi K, Shiraki Y, Ogawa M (1999). Bacterial contamination of ready to eat foods and fresh products I retail shops and food factories. Journal of Food Protection, 62: 644-649.

8. Kerr KG, Birkenhead D, Seale K, Major J, Hawkey PM (1993). Prevalence of Listeria spp. on the hands of food workers. Journal of Food Protection, 56: 525-527.

9. MacGowan AP, Bowker R, Mclauchlin J (1994). The occurrence and seasonal changes in the isolation of Listeria spp. in shop bought foodstuffs, human faeces, sewage and soil from urban sources. Journal of Food Microbiology, 21: 325-334.

10. Melngaile A, Ciekure E, Valcina O (2004). Microbiological quality of meat preparations and meat products. Foodbalt, 61-65.

11. Pelczar MJ, Chane CS, Kreig NR (2006). Microbiology. (5th ed.). New Delhi: Tata McGraw-Hill Publishing Company Limited.

12. Regulation (EC) No 2073/2005 on Microbiological criteria for food stuffs.

13. Saadia M, Hassanein E (2010). Microorganisms Found in Fast and Traditional Fast Food. Journal of American Science, 6: 515-531.

14. Schaffner DW (2007). Microbial risk analysis of foods: Emerging Issues in Food Safety. Washington, USA: American Society for Microbiology, 270 S.

15. Stiles ME (1981). Enterobacteriaceae associated with meats and meat handling. Applied and Environmental Microbiology, 1: 867-872.

16. Uyttendaele M, De Troy P, Debevere J (1999). Incidence of Salmonella, Campylobacter jejuni, Campylobacter coli and Listeria monocytogenes in poultry carcasses and different types of poultry products for sale on the Belgian retail market. Journal of Food Protection, 62: 735-740.

17. Wheatley P, Giotis ES, McKevitt AI (2014). Effects of slaughtering operations on carcass contamination in an Irish pork production plant. Irish Veterinary Journal, 67:1.

18. Lim CM, Fernando SY, Wei C (1996). Occurrence of Listeria monocytogenes, Salmonella spp., Escherichia coli and E. coli 0157: H7 in vegetable salads. Food Control, 7: 135140. 